\title{
A 'new' syndrome of mental retardation with characteristic facies and brachyphalangy
}

\author{
AlASDAir G. W. HUNTER, PHYLlis J. MCALPINE, NOREEN L. RUDD, \\ AND F. CLARKE FRASER \\ From the Division of Genetics, Department of Pediatrics, University of Manitoba and Health Sciences \\ Centre, Winnipeg, Manitoba; the Department of Genetics, Hospital for Sick Children, Toronto, Ontario; and \\ the Department of Medical Genetics, The Montreal Children's Hospital, Montreal, Quebec, Canada
}

SUMMARY This paper describes 6 individuals, occurring in 3 generations of a single family, who were affected by a distinct syndrome which included: retardation and microcephaly; a small oval face with $\overrightarrow{+}$ almond-shaped eyes, droopy eyelids, a small nose, and small downturned mouth; minor acral skeletal anomalies, and short stature. Craniosynostosis, heart defects, and limited elbow extension were seen $\omega_{0}^{\circ}$ less frequently. Expression was variable and parents who were in the direct vertical line of trans- 0 mission of the syndrome showed few, if any, overt signs of the disease. However, the metacarpal/ phalangeal profile of the parents showed a similar pattern to that seen in the affected individuals, and it is suggested that this profile may be the most sensitive indicator of carrier status.

It is important to distinguish, within the heterogeneous category of 'mental retardation', those cases with specific syndromes, so that the families concerned can be advised more accurately about the prognosis, both medical and genetic. This paper describes a new familial syndrome appearing in 6 individuals over 3 generations, whose major features include: retardation of varying severity, a characteristic facies, and minor acral skeletal anomalies with a characteristic pattern of phalangeal shortness. The distribution of this syndrome in this kindred is

Received for publication 7 March 1977 compatible with autosomal dominant inheritan $\vec{\theta}$ with reduced penetrance.

\section{Family history}

The family was of British extraction, and was ascertained independently through a girl in Montreal (Fig. 1, V.14), and a boy in Toronto (Fig. 1, V.1) who $\frac{\mathrm{D}}{2}$ was studied as part of a project on craniosynostosis $\stackrel{\varrho}{\Rightarrow}$ (Family 9, Hunter and Rudd, 1977). The probands were third cousins. There was considerable variation in severity of expression of the syndrome among the six retarded individuals, and all parents of affected persons were of normal intelligence.

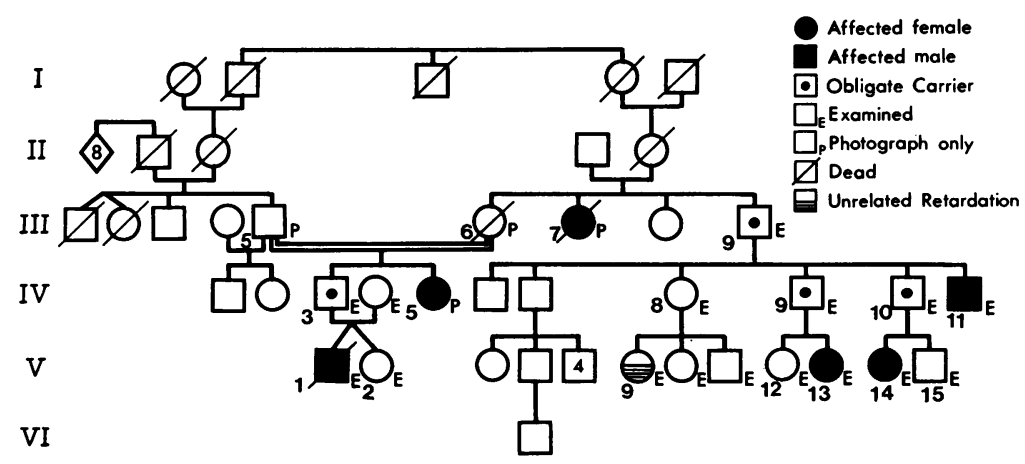

Fig. 1 Pedigree of family 

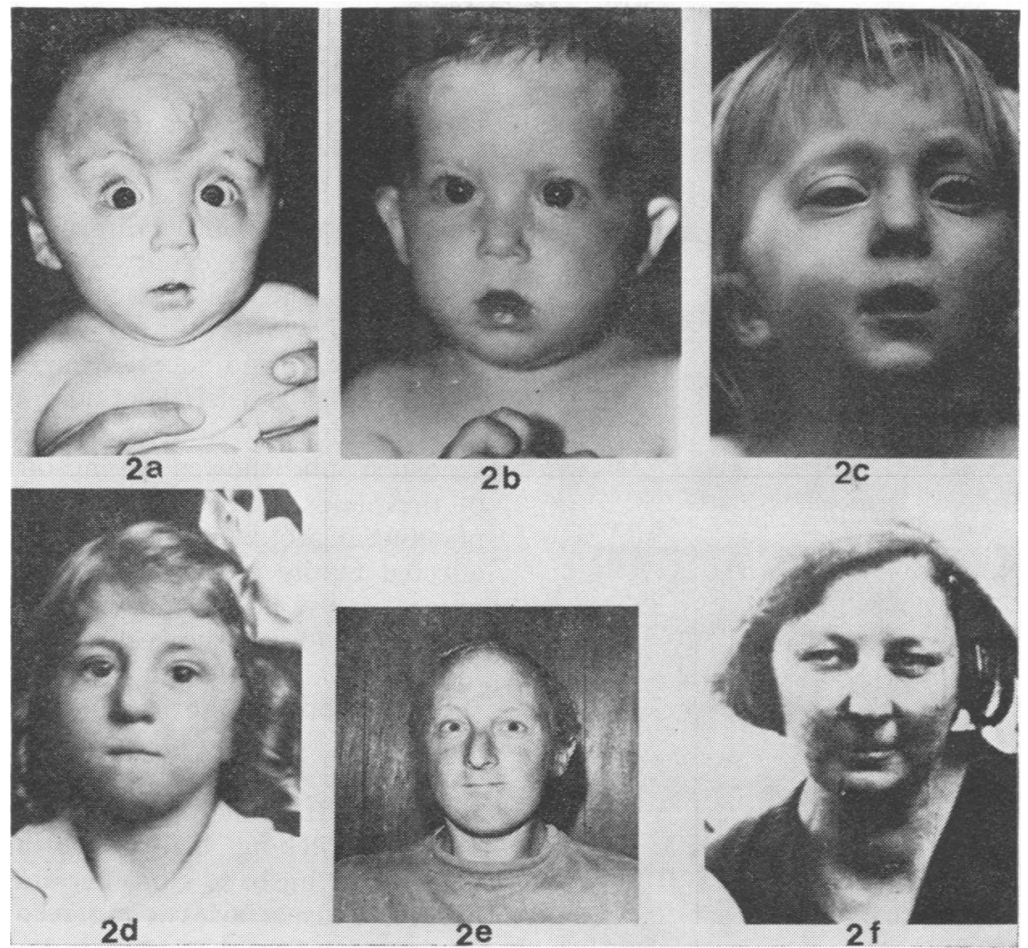

Fig. 2 Photographs of affected individuals illustrating oval facies, mild jowly appearance, almond-shaped eyes, frequently with droopy lids, and small mouth $(a) V .1 ;(b) V .13 ;(c) V .14 ;(d) I V .5 ;(e) I V .11 ;(f) I I I .7$.

\section{Case histories}

\section{AFFECTED PERSONS \\ V.1 (To. U.)}

This boy was the first of dizygotic twins delivered by caesarian section because of arrested labour. He weighed $2840 \mathrm{~g}$ at birth. Operations for complete craniosynostosis were carried out at 1 and 2 months of age, and at 8 months of age a metopic prominence, which was found to be a leptomeningeal cyst, was removed. His facial appearance (Fig. 2a) was typical of the affected members of the family, with small almond-shaped eyes, small blunt nose, the impression of a long philtrum, and a very small downturned mouth with fine lips.

He walked at the age of 3 years and at $4 \frac{1}{2}$ years his IQ was assessed at 38 on the Stanford-Binet scale. At that time his occipitofrontal circumference (OFC) and height were less than the third centile. He had a left esotropia, small crowded teeth, incomplete extension at the elbows, and a right inguinal hernia. Radiographic examination showed a spina bifida occulta at L5-S1 and coned epiphyses of the middle phalanges of fingers 2 and 5 bilaterally (Fig. 3a). The metacarpal-phalangeal profile and ratios were typical of affected family members and are summarised in Fig. 4 and the Table respectively. Routine haematological and biochemical studies, a urine amino acid chromatogram, and a mucopolysaccharide screen were normal.

He died at the age of 13 years after a brief bout of pneumonia. Necropsy showed pronounced dilatation of the ventricles and cerebral atrophy.

\section{(V.13 (B.U.)}

This girl (Fig. 2b) weighed $3230 \mathrm{~g}$ at birth after a normal pregnancy and delivery. She sat at 6 months and walked at 18 months of age. Language was delayed, with failure to link words by the age of 3 years. Toilet training was normal. At the age of 3 years she was $83 \mathrm{~cm}$ tall $(<3$ rd centile) and had an OFC of $47 \mathrm{~cm}(<3 \mathrm{rd}$ centile). Her hands were small with a characteristic metacarpal-phalangeal profile (Fig. 4) and the epiphyses of the right 2 nd and 4 th and of the left 2 nd, 3rd, and 4th toes were coned.

V.14 (C.U.)

This girl (Fig. 2c) weighed $2325 \mathrm{~g}$ at birth after a normal pregnancy and delivery. She sat at 8 months, walked at 18 months, and said her first words at 24 

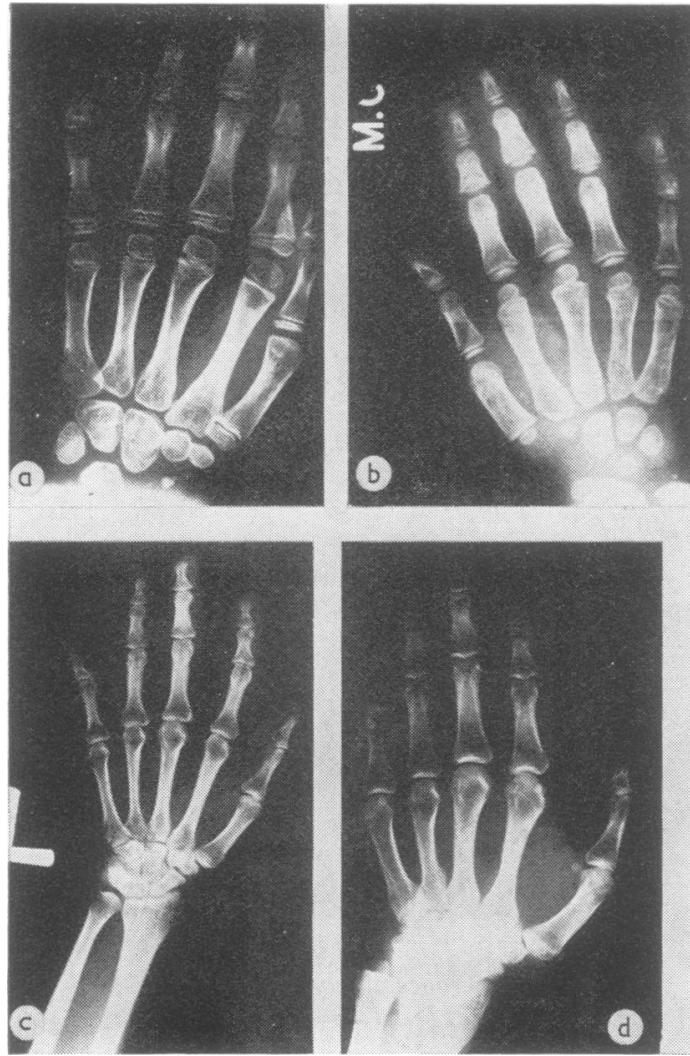

Fig. 3 Hand radiographs of affected persons showing variable coning of epiphyses and phalangeal shortness, and the overall distal and middle phalangeal shortness, not apparent without mensuration. (a) V.1; (b) V.14; (c) IV.5; (d) IV.II. months of age. At the age of 3 years she had cor $\frac{\widehat{D}}{2}$ rection of a convergent squint. At the age of $5 \frac{1}{2}$ year\$ her development was estimated to be between $2 \frac{1}{2}$ and 3 years. On examination at the age of $6 \frac{1}{2}$ years, she had? the characteristic facial appearance of affected family members with a suggestion of epicanthus, almond? shaped eyes, a small downturned mouth measuring $23 \mathrm{~mm}$, somewhat droopy eyelids, and borderline low-set ears. She was $94 \mathrm{~cm}$ tall $(<3 \mathrm{rd}$ centile) and haof an OFC of $47 \cdot 4 \mathrm{~cm}(<3 \mathrm{rd}$ centile). Her skull wå plagiocephalic and face asymmetric because of क right coronal and left lambdoid synostosis. Radio $\rightarrow$ graphs confirmed right coronal and left lambdoid synostosis and showed coning of several epiphyses of the hands (Fig. 3b) and feet. Her metacarpals phalangeal profile and ratios were characteristic o affected family members (Fig. 4, Table). A harsh grade $3 / 6$ systolic murmur with fixed splitting of the second sound was shown by cardiac catheterisation to be an atrial septal defect. An electroencephalogranf showed minor diffuse irregularities and asymmetryo with poor background activity. Q and G-banded chromosome analyses showed a normal 46,XX,13s+c karyotype. It is interesting that the mother of V.14 sought counselling before she had any childrere because her husband's brother and aunt were retarb ded. The unusual facies was not recognized and she was given a prognosis that was erroneously reassuring $\overrightarrow{0}$

IV.5 (E.U.)

This woman was born after a normal pregnancy delivery. Her parents were first cousins. At the age of 39 her IQ was estimated to be 52-67 on the Stanford Binet scale; she was toilet-trained, could feed herself and had some simple speech. Her height was $134 \mathrm{~cm}$. ( $<3$ rd centile), weight $32 \cdot 8 \mathrm{~kg}(<3 \mathrm{rd}$ centile), and

Table Standard deviations from mean of length of distal phalanges $\div 5$ th metacarpal

\begin{tabular}{|c|c|c|c|c|c|c|c|c|c|}
\hline & & D1/M5 & D2/M5 & $D 3 / M 5$ & $D 4 / M 5$ & D5/MS & Total & Mean & \\
\hline \multirow{5}{*}{ Patients } & IV.5 & -3.00 & $-2 \cdot 00$ & $-2 \cdot 50$ & $-2 \cdot 67$ & -2.00 & $-12 \cdot 2$ & -2.43 & \\
\hline & IV.11 & $-6 \cdot 00$ & $-3 \cdot 50$ & -4.00 & $-4 \cdot 00$ & -3.00 & -20.5 & $-4 \cdot 10$ & \\
\hline & V.1 & -7.00 & $-4 \cdot 00$ & $-5 \cdot 50$ & $-4 \cdot 50$ & -3.00 & -24.0 & $-4 \cdot 80$ & \\
\hline & V.14 & -6.50 & -1.50 & $-1 \cdot 50$ & $-2 \cdot 00$ & -1.50 & $-12 \cdot 5$ & -2.50 & \\
\hline & V.13 & $-2 \cdot 00$ & -0.67 & -0.67 & -1.00 & $-1 \cdot 50$ & -05.8 & $-1 \cdot 17$ & \\
\hline \multirow[t]{2}{*}{ Mean } & & $-4 \cdot 90$ & $-2 \cdot 33$ & $-2 \cdot 83$ & $-2 \cdot 83$ & $-2 \cdot 20$ & & -3.00 & \\
\hline & 111.9 & -1.00 & $-1 \cdot 50$ & $-2 \cdot 50$ & $-2 \cdot 00$ & $-1 \cdot 50$ & -08.5 & $-1 \cdot 70$ & \\
\hline \multirow{3}{*}{$\begin{array}{l}\text { Obligate } \\
\text { carriers }\end{array}$} & IV.3 & $-1 \cdot 33$ & $-2 \cdot 00$ & $-2 \cdot 00$ & $-1 \cdot 50$ & -2.00 & $-08 \cdot 3$ & -1.77 & \\
\hline & IV.9 & -1.67 & $-1 \cdot 50$ & $-1 \cdot 50$ & $-2 \cdot 00$ & $-1 \cdot 50$ & $-08 \cdot 2$ & -1.63 & \\
\hline & IV.10 & $-2 \cdot 00$ & $-2 \cdot 00$ & $-2 \cdot 50$ & -1.50 & $-1 \cdot 50$ & $-09 \cdot 5$ & -1.90 & \\
\hline \multirow[t]{3}{*}{ Mean } & & -1.50 & $-1 \cdot 75$ & -2.00 & $-1 \cdot 75$ & -1.63 & & -1.73 & \\
\hline & IV.8 & $-1 \cdot 00$ & -0.33 & -0.33 & -0.67 & -0.33 & $-02 \cdot 7$ & -0.53 & \\
\hline & V.2 & $-2 \cdot 33$ & -2.00 & $-2 \cdot 00$ & -3.00 & -1.50 & $-10 \cdot 3$ & $-2 \cdot 17$ & \\
\hline \multirow[t]{3}{*}{ At risk to carry } & V.9 & $+1 \cdot 00$ & +1.00 & +0.50 & $+1 \cdot 50$ & $+1 \cdot 50$ & $+05 \cdot 5$ & $+1 \cdot 10$ & \\
\hline & V.12 & -0.50 & 0.00 & 0.00 & +0.50 & 0.00 & $00 \cdot 0$ & 0.00 & \\
\hline & V.15 & +0.33 & +0.33 & 0.00 & +1.00 & 0.00 & $+01 \cdot 7$ & +0.33 & \\
\hline
\end{tabular}

Note: The numbers in columns are standard deviations from the age appropriate means of the length of the distal phalanges divided by the length of the Sth metacarpal. 

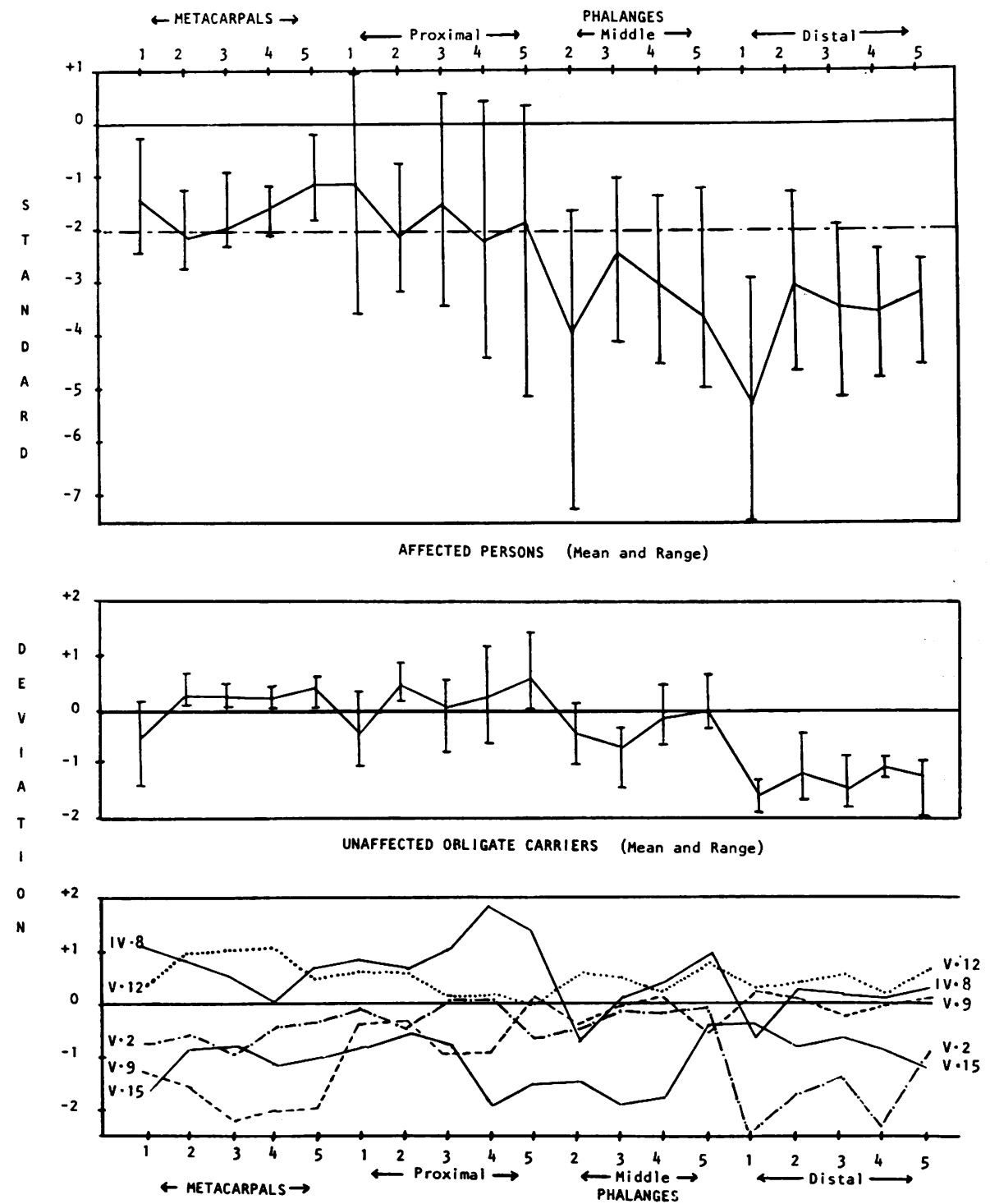

Fig. 4 The upper two graphs show the mean and range of standard deviations from the age appropriate population mean (Poznanski, 1974) of the length of individual hand bones in patients (upper) and obligate carriers (middle). The bottom graph shows the metacarpal-phalangeal profiles of those unaffected persons who were at risk to inherit the syndrome.

OFC $49 \mathrm{~cm}$ ( $<3$ rd centile). Her facial appearance was remarkably similar to that of the other affected family members (Fig. 2d), with a flat oval face, almondshaped eyes, small downturned mouth, and small chin. Secondary sexual characteristics were normal and menses were irregular. A urine amino acid chromatogram, and G- and R-banded karyotypes were normal. The middle phalanges of the index and 5th fingers were considerably shortened (Fig. 3c); the phalangeal-metacarpal profile and ratios were typical of affected family members (Fig. 4, Table).

IV.11 (R.U.Jr.)

This man was born after a normal pregnancy and 


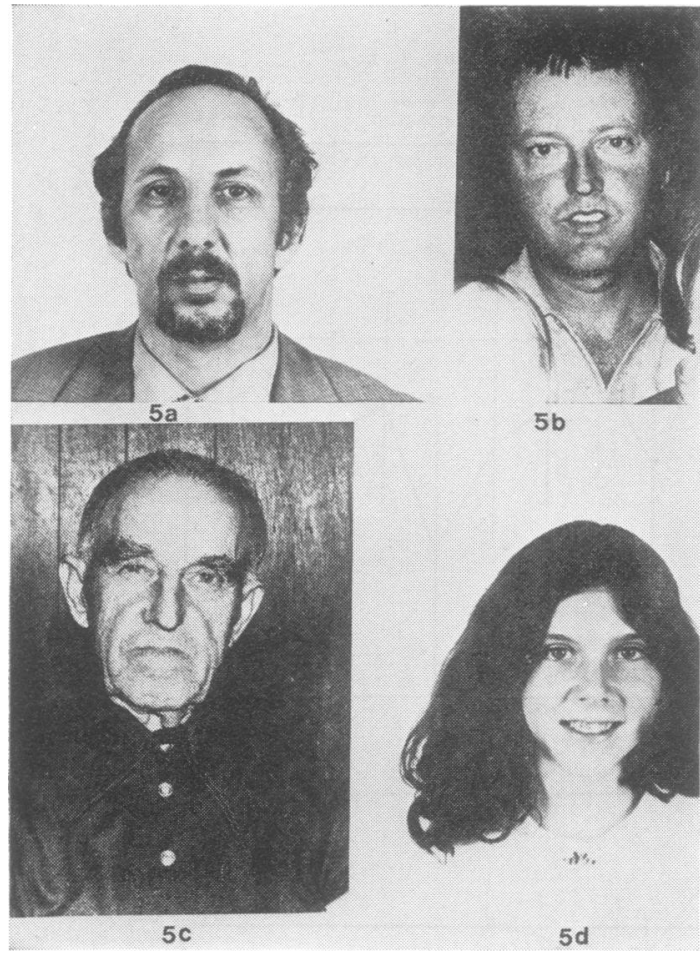

Fig. 5 Photographs of obligate carriers (a) IV.3; (b) IV.9; (c) III.9; and V.2 (d) who was at risk to inherit the syndrome and who showed the typical carrier metacarpalphalangeal profile. IV.9 has an oval face and small mouth. The others have no facial stigmata of the syndrome.

delivery. Progress in school was slow and he did not enter high school. Currently he can sign his name, write a few simple words, and help his brother about the farm. Puberty was delayed until the age of 21 years and he continues to show sparse facial hair. He is $165 \mathrm{~cm}$ tall and has an OFC of $54.2 \mathrm{~cm}$. He had the typical facial appearance of affected family members with an oval, slightly heavy jowled face, almond eyes, a small downturned mouth $(32 \mathrm{~mm})$, and small chin (Fig. 2e). He had a grade $2 / 6$ ejection systolic murmur at the left costal margin which was not considered to be of clinical significance. He had mild bilateral clinodactyly of the 2nd, 4th and 5th fingers, and the distal thumb and great toe were extremely short and bulbous (Fig. 3d). The metacarpalphalangeal profile and ratios were typical of affected family members (Fig. 4, Table).

\section{III.7 (F.U.)}

This woman was dead at the time of study but was described as being feeble-minded. She had lived at home, carried out simple tasks, and could read a few simple words. Her photograph showed a remarkably $\frac{3}{8}$ similar appearance to other affected family members (Fig. 2f).

OBLIGATE CARRIERS LACKING CLINICAL MANIFESTATIONS

IV.3 (H.U.)

This man (Fig. 5a) was the father of patient V.1. He was of normal intelligence, was $167 \mathrm{~cm}$ tall, and had an OFC of $54.6 \mathrm{~cm}$. His facial appearance wasu normal and his mouth measured $46 \mathrm{~mm}$ (Fig. 5a). Hes had some limitation of full extension at the elbows, his metacarpal-phalangeal profile and ratios were similar to that of other obligate carriers and arew summarised in Fig. 4 and the Table, respectively A Giemsa banded karyotype was 46.XY.

IV.9 (K.U.)

This man (Fig. 5b) was the father of patient V.13. Het was a farmer and of normal intelligence, height, and $P$ weight. He had a somewhat round face and smallo mouth $(35 \mathrm{~mm})$ but the remainder of the physical examination was unremarkable. His metacarpalphalangeal profile and ratios were typical of un-क्ष affected family members who were carriers (Fig. 4,,$\frac{7}{6}$ Table). A Giemsa stained karyotype revealed the presence of the same D-group marker chromosome seen in V.14.

\section{IV.10 (C.U.)}

This man was the father of patient V.14. He was normal intelligence, $187 \mathrm{~cm}$ tall, had an OFC of $61 \bar{\circ}$ $\mathrm{cm}$, and his mouth was $47 \mathrm{~mm}$ wide. His metacarpal-ö phalangeal profile and ratios were characteristic of $\mathbb{Q}_{\mathscr{Q}}$ that shown by unaffected obligate carriers (Fig. $4, \overrightarrow{\vec{F}}$ Table). Conventional Giesma, G- and Q-banded 3 chromosome studies showed a 46,XY,13s+ karyotype. The marker chromosome was visible on con-o ventional Giemsa analysis though its nature was not clear by this technique.

III.9 (R.U.Sr.)

This man (Fig. 5c) was the father of patient IV.11, and was in his 70's at the time of the examination. 3 He had been a farmer and in good health all his life. He was $170 \mathrm{~cm}$ tall, his mouth measured $41 \mathrm{~mm}$, and his facial appearance and physical examination were? entirely normal. The metacarpal-phalangeal profile and ratios were similar to the other unaffected $N$ obligate carriers in the family (Fig. 4, Table).

III.5 (A.U.)

N The father of IV. 5 and IV. 3 was dead at the time of the study and no clinical or radiological details weré available. A photograph did not show any features of the syndrome. 
III.6 (R.U.)

The mother of IV.5 and IV. 3 was dead at the time of the study and no clinical or radiological details were available. A photograph suggested a small mouth.

\section{UNAFFECTED PERSONS AT RISK TO BE} CARRIERS

It was possible to examine the following persons: V.2, V9.12, and IV.8. All were of normal height, weight, appearance, and intelligence, with the exception of a girl (V.9) who was retarded. This girl weighed $2834 \mathrm{~g}$ (7lb 4oz) at birth after a normal pregnancy and delivery. At the age of 14 years her height was at the 50th centile and her head circumference at the 30 th centile. She was considered to have a trivial pulmonary stenosis. She did not resemble the other family members with retardation in appearance, and her metacarpal-phalangeal profile and ratios were not typical of affected family members or the unaffected obligate carriers (Fig. 4, Table). She does not appear to be affected with the same syndrome. G- and Q-banded chromosome studies of V.15 showed a 46,XY karyotype.

Hand radiographs were available on V.2, V.9, V.12, V.15, and IV.8. Of these 5 individuals, only V.2 (Fig. $5 d)$ showed the patterns of relative shortness of the distal phalanges that was typical of the unaffected obligate carriers (Fig. 4, Table). V.15 had generally small hands but lacked the pattern of relative shortness of the distal phalanges, as did all the other potential carriers.

\section{Dermatoglyphs}

Dermatoglyphic analysis was carried out on several affected and non-affected family members but no consistent abnormalities or unusual features were seen.

\section{Segregation analysis}

Segregation analysis using the metacarpal-phalangeal profile as the ultimate criterion of carrier status gives 5 affected, 5 unaffected, and 2 unknown (see Discussion). In this analysis V.1, V.14, IV.10, and III.9 were excluded as the index cases of their sibship, and IV.3 and IV.4 because of parental consanguinity. This result is consistent with segregation of an autosomal dominant gene.

\section{Linkage analysis}

Under the hypothesis that this syndrome relates to a dominant allele at an autosomal gene locus, designated as $U$, classical linkage studies were undertaken to determine if linkage could be shown between the
$U$ locus and a locus determining a genetic marker expressed in blood and segregating in this family. The lod scores (summarized in the Appendix) were obtained by the mark III version (Côté, 1975) of the linkage program based on Edwards' marker algebra (Edwards, 1972). If the $U$ locus is on the same chromosome as any of the marker loci the lod scores indicate that at least one crossover must have occurred between the $U$ locus and each of the following loci: $A D A$ (adenosone deaminase), $A C P_{1}$ (red cell acid phosphatase), $P G M_{1}$ (phosphoglucomutase $_{1}$ ), GPT (glutamic-pyruvate transaminase), $H p$ ( $\alpha$-haptoglobin), $C o$ (Colton blood group), Kell blood group, $M N S s$ blood group, and $R h$ (Rhesus blood group). These findings suggest that the $U$ locus is not closely linked to any of these marker loci. Three generation $U: A B O$ blood group and $U:$ Kidd blood group segregation data were obtained and in each instance the segregation was 2 nonrecombinants: 0 recombinants. Only slightly positive lod scores were obtained between $U$ and Do (Dombrock blood group) and between $U$ and $S e$ (secretor status) as the phase of the doubly heterozygous parents could not be determined. However, as the positive lod scores are not large and only a limited number of offspring could be scored, no conclusions can be drawn from these data regarding the linkage of the $U$ locus to $A B O, K i d d, D o$, and Se.

\section{Discussion}

This family presents a morphologically distinct syndrome that appears with varying severity over three generations. The major manifestations of the syndrome include: retardation and microcephaly; a characteristic facial appearance with a small, oval, slightly jowly face, almond-shaped eyes, droopy lids, small nose, and small downturned mouth; minor acral-skeletal anomalies and short stature. Craniosynostosis, limited extension at the elbows, and cardiac abnormalities were seen less frequently. The degree of retardation ranged from severe, and requiring institutional care, to mild with minor motor delay and some speech delay. Four of the five living affected individuals had an OFC at or below the third centile and these individuals were also less than the third centile for height.

The acral-skeletal changes are subtle but characteristic, and they serve to illustrate the usefulness of metacarpal-phalangeal profiles and ratios. Visual inspection of hand radiographs of both probands (Fig. 3a and b) showed coned epiphyses and shortness of the middle, second, and fifth phalanges which suggested a type $A_{4}$ (McKusick, 1975) brachydactyly, whereas the hands of patient IV.II suggested type D brachydactyly or stub thumbs (Fig. 3d). Only after 
actual measurements of the metacarpal and phalangeal bones were taken from radiographs (Poznanski, 1974) was it realised that all affected individuals had generally small hands, and that this shortness was most pronounced in the distal and middle phalanges (Fig. 4, Table); such changes would perhaps best be classified as a mild form of type B brachydactyly. There was a tendency toward maximal involvement of the distal phalanx of the thumb. Villeverde and $\mathrm{Da}$ Silva (1975) have reported an increased frequency of shortness of the distal phalanx of the thumb in mentally retarded patients and have pointed to an association of stub thumbs with cranial anomalies and short stature. It is not possible to recognise affected persons similar to our patients in their paper, and it is not clear whether or not they systematically analysed other digits.

Inspection of the pedigree (Fig. 1) shows clearly that there is frequent non-penetrance of the syndrome, which makes identification of the non-manifesting carrier difficult for the genetic counsellor. With the exception of a small mouth in IV.9 and some limitation of movement at the elbow in IV.3 all parents of affected children appeared entirely normal and were of normal intelligence. Hand radiographs of all the unaffected obligate carriers were normal to inspection, but precise metacarpal-phalangeal measurements, though within normal limits, showed the same pattern of relative shortness of the distal and middle phalanges as seen in the patients (Fig. 4).

A numerical assessment of this pattern can be made by comparing the relative lengths of the different hand bones, as outlined by Poznanski(1974). The results of the most informative comparisons are shown in the Table. Metacarpal 5 showed the least variation, was close to the population mean in both the patients and unaffected obligate carriers, and thus was the most useful denominator. In patients, the quotient D1/M5 deviated furthest from normal though the values for all distal phalanges were more than two standard deviations below the mean. The one exception was the youngest patient, V.13, who had overall small hands, including the metacarpals. She also had a very mild degree of retardation and it will be of interest to observe any changes in the relative lengths of the hand bones with time. All the obligate carriers show the same tendency of the D1-5/M5 quotients to fall well below the mean (Table). The value of D1/M5 does not, however, stand out as the most discriminating value as it did in the case of the affected persons.

Of the 5 unaffected persons examined who were at varying risks to inherit the syndrome, only V.2 had a metacarpal-phalangeal profile (Fig. 4) and ratios (Table) that were typical of the obligate carriers. If the study of additional patients and obligate carriers supports these findings, the metacarpal-phalangeal profiles and ratios may serve as the most sensitive $\frac{\mathbb{Q}}{\Omega}$ indicators of carrier status in unaffected individuals.

This syndrome occurred with varying expression $\mathbb{D}$ in both males and females over three generations, $\underset{\oplus}{+}$ with several instances of lack of penetrance. The $\vec{\Rightarrow}$ pattern of autosomal dominant inheritance is con- $\stackrel{\vec{\rho}}{\stackrel{9}{2}}$ sistent with the expression of a single mutant geneo though a cytogenetic explanation is also possible. An $\underline{\overline{0}}$ undetectable translocation where the breakpoint was $\frac{\bar{m}}{\frac{1}{2}}$ within a gene resulting in loss of function might $\stackrel{\Phi}{\Omega}$ cause minor skeletal changes in the carriers of this rearrangement whereas the retarded patients would ${ }_{\vec{D}}^{\infty}$ represent the unbalanced products of meiosis. Patients with 7 p-syndrome may show retardation, $\vec{\omega}$ craniosynostosis, ptosis, and limited extension at the elbow in common with our patients (McPherson et al., 1976), and Wilson et al. (1973) have suggested. that the giant satellite of chromosome 13 in their $\overrightarrow{+}$ patient represented a translocated deletion of part of the short arm of chromosome 7. Careful karyotype analysis of IV.5 using G- and R-banding and of V.14 using G- and Q-banding failed to disclose any chromosome abnormality. A marker chromosome $\vec{\square}$ number 13 , with short $\mathrm{p}$ arms and a prominentक satellite, was seen in IV.9 and 10, and V.15 but was® absent in IV.3 and IV.5. Thus, there is no evidence of any chromosome abnormality in our patients or their parents.

The gradual progression from a mild abnormality metacarpal-phalangeal profile, with occasional minor physical anomalies (small mouth, elbow limitationi)o through increasing retardation, which may tes accompanied by major anomalies and metacarpal phalangeal shortness, is compatible with the variable expressivity seen with dominant genes. It is to bo expected that parents of affected children would be among the mildly affected because the retardec $B$ individuals have reduced genetic fitness.

The authors are indebted to Ms M. Lewis and Ms $\mathrm{H}_{0}$ Kaita, Rh Laboratory Winnipeg for determining the blood group phenotypes (Medical Research. Council of Canada grant MA-3391). Ms J. Bell, MS्S B. Fifik, and Ms L. Lucciola provided expert technicaR assistance in the determination of enzyme phenotypes (Medical Research Council of Canada grant MA $\rightarrow$ 4061, and the Children's Hospital of Winnipeg. Research Foundation, Inc.). We are grateful to Vera Markovic, Ph. D., Cytogeneticist, Surrey Place Centre, Toronto, and to Dr Dagmar KalousekN Department of Pathology, Montreal Children'心 Hospital, who carried out the cytogenetic studies? This work was partly supported by a Medicad Research Council of Canada grant to the Medicif Genetics group in Montreal. 
Appendix Summary of lod scores obtained between $U$ and marker loci

\begin{tabular}{|c|c|c|c|c|c|c|c|}
\hline \multirow[t]{2}{*}{ Locus } & \multirow[t]{2}{*}{ Heterozygotes } & \multirow{2}{*}{$\begin{array}{l}\text { Number of } \\
\text { children tested }\end{array}$} & \multicolumn{5}{|c|}{ Lod scores for recombination fractions of } \\
\hline & & & 0.05 & $0 \cdot 10$ & $0 \cdot 20$ & $0 \cdot 30$ & $0 \cdot 40$ \\
\hline$A B O^{*}$ & $1 \mathbf{M} \dagger$ & 2 & 0.558 & 0.511 & 0.408 & 0.292 & 0.158 \\
\hline$A D A$ & $2 \mathrm{M}$ & 4 & $-2 \cdot 721$ & -1.842 & -0.990 & -0.520 & -0.212 \\
\hline$A C P_{1}$ & $3 \mathbf{M}$ & 6 & -3.439 & $-2 \cdot 284$ & $-1 \cdot 183$ & -0.596 & -0.230 \\
\hline $\mathrm{Co}$ & $1 \mathrm{M}$ & 5 & -0.186 & 0.022 & $0 \cdot 124$ & 0.095 & 0.031 \\
\hline Do & $2 \mathrm{M}$ & 7 & 0.022 & 0.020 & 0.014 & 0.007 & 0.002 \\
\hline$G P T$ & $1 \mathrm{M}$ & 5 & -0.721 & -0.444 & -0.194 & -0.076 & -0.018 \\
\hline$H p$ & $1 \mathrm{M}$ & 5 & -0.721 & -0.444 & -0.194 & -0.076 & -0.018 \\
\hline Kidd & $1 \mathrm{M}$ & 2 & 0.558 & 0.511 & 0.408 & 0.292 & 0.158 \\
\hline Kell & $1 \mathrm{M}$ & 2 & -1.000 & -0.699 & -0.398 & -0.222 & -0.097 \\
\hline Secretor & $1 \mathrm{M}$ & 5 & $0 \cdot 171$ & $0 \cdot 143$ & 0.089 & 0.043 & 0.011 \\
\hline MNSs & $2 \mathrm{M}$ & 7 & -2.442 & -1.586 & -0.786 & -0.373 & -0.132 \\
\hline$P G M_{1}$ & $3 \mathbf{M}$ & 9 & $-1 \cdot 181$ & -0.671 & -0.253 & -0.088 & -0.019 \\
\hline$R h$ & $3 \mathbf{M}$ & 9 & $-3 \cdot 163$ & -2.030 & -0.980 & -0.449 & $-0 \cdot 150$ \\
\hline
\end{tabular}

*Loci abbreviations as in text

†M Male

\section{References}

Côté, G. B. (1975). Centromeric linkage in man. Ph. D. Thesis, University of Birmingham, Birmingham, England.

Edwards, J. H. (1972). A marker algebra. Clinical Genetics, 3, 371-380.

Hunter, A. G. W., and Rudd, N. L. (1977). Craniosynostosis. Part II : Coronal synostosis; its familial characteristics and associated clinical findings in 109 patients who lacked bilateral polysyndactyly or syndactyly. Teratology, 15, 301310.

McKusick, V. A. (1975). Mendelian inheritance in Man, 4th ed., p. 42. The Johns Hopkins University Press, Baltimore.

McPherson, E., Hall, J. B., Hickman, R., Gong, B. T., Norwood, T. H., and Hoehn, J. (1976). Chromosome 7 short arm deletion and craniosynostosis. A $7 \mathrm{p}$-syndrome. Human Genetics, 35, 117-123.

Poznanski, A. K. (1974). The Hand in Radiologic Diagnosis, pp. 29-44. W. B. Saunders, Philadelphia.

Villeverde, M. M., and Da Silva, J. A. (1975). Distal brachyphalangy of the thumb in mental retardation. Journal of Medical Genetics, 12, 401-404.

Wilson, M. G., Fujimoto, A., Shinno, N. W., and Towner, J. W. (1973). Giant satellites or translocation? Cytogenetics and Cell Genetics, 12, 209-214.

Requests for reprints to Dr Alasdair G. W. Hunter, Department of Genetics, Health Sciences Centre, 700 William Ave, Winnipeg, Manitoba R3E OZ3, Canada. 